\title{
Self-terminating versus exhaustive processes in rapid visual and memory search: An evaluative review
}

\author{
TRISHA VAN ZANDT \\ Northwestern University, Evanston, Illinois \\ and \\ JAMES T. TOWNSEND \\ Indiana University, Bloomington, Indiana
}

\begin{abstract}
A major issue in elementary cognition and information processing has been whether rapid search of short-term memory or a visual display can terminate when a predesignated target is found or whether it must proceed until all items are examined. This study summarizes past and recent theoretical results on the ability of self-terminating and exhaustive models to predict differences in slopes between positive (target-present) and negative (target-absent) set-size functions, as well as position effects. The empirical literature is reviewed with regard to the presence of slope differences and position effects. Theoretical investigations demonstrate that self-terminating models can readily predict the results often associated with exhaustive processing, but a very broad class of exhaustive models is incapable of predicting position effects and slope differences typically associated with self-termination. Because position effects and slope differences are found throughout the rapid search literature, we conclude that the exhaustive processing hypothesis is not tenable under common experimental conditions.
\end{abstract}

Since the earliest work in experimental psychology, researchers have been attempting to uncover the architecture of various simple mental processes through the measurement of reaction time (RT; Cattell, 1886/1947; Donders, 1868/1969; Wundt, 1894). In RT tasks, an observer is presented with a stimulus, and the time that elapses between its onset and the execution of a response is recorded. The changes in RT under different modes of stimulation or different response requirements are assumed to provide information about the component mental processes and how these components are linked together. Luce (1986), Posner (1978), Townsend and Ashby (1983), and Welford (1980) provide reviews and somewhat differing perspectives on empirical and theoretical research in which RT has been used to study mental processes.

This paper focuses on two simple paradigms used extensively to study simple mental processes: rapid visual and memory search. In the search task, an observer is

\footnotetext{
We wish to express our appreciation to one anonymous reviewer, as well as to C. W. Eriksen, W. K. Estes, R. W. Proctor, R. Schweickert, and J. Theios for helpful comments on an earlier draft of this paper. This research was supported by NSF Grant BNS-831-9377, awarded to J.T.T. Correspondence should be addressed to J. T. Townsend, Department of Psychology, Indiana University, Bloomington, IN 47405 (e-mail: jtownsen@ucs.indiana.edu).
}

presented with a list of items, called the "search set." The search set is usually composed of letters or numbers, but pictures, words, and tones have also been used. The observer is required to indicate whether a "target" item is present in the search set by executing a positive ("yes") or negative (" "no") response. In memory search tasks, the search set is presented to the observer prior to the target item. When the target is presented, the observer must "search" the items held in memory to decide whether or not the target has been seen before. In visual search tasks, the search set is presented after the target. The observer must "scan" the items of the visual display to decide whether the target is present among them. Hybrid or visual/memory search tasks are characterized by multiple targets; a list of items is held in memory to be compared with an array of items presented visually. In all search tasks (memory, visual, and visual/memory), the observer is required to respond positively if any match is found between the items held in memory and those presented visually, and negatively if no match is found.

The surface distinction between visual and memory search consists in the number of items held in memory and the number of items presented visually. The results in both visual and memory search have been strikingly similar, enough so that some investigators (e.g., Gilford \& Juola, 1976) have suggested that the locus of search 
is the same in the two paradigms, although other considerations argue against that conclusion (Hockley, 1984; Townsend, 1974; Townsend \& Roos, 1973). In any case, analogous modeling issues arise within both paradigms, regardless of where the search occurs.

These paradigms were initially designed primarily to distinguish between serial (one at a time) and parallel (simultaneous) processing of several distinct stimuli (Atkinson, Holmgren, \& Juola, 1969; Estes \& Wessel, 1966; Murdock, 1971; Sternberg, 1966; Townsend \& Roos, 1973). Apart from serial and parallel processing, other aspects of the system were soon noted to be equally important in determining RT (Townsend, 1974), with the capacity of the system being one of these. Partly because of the contribution of these other characteristics of processing, serial and limited capacity parallel models can produce identical patterns of mean RT (Townsend, 1972). Nevertheless, theoretical and empirical research subsequently developed a number of alternative designs that offer considerable promise for discriminating between serial and parallel models (C. W. Eriksen, Webb, \& Fournier, 1990; Schweickert, 1978; Schweickert \& Townsend, 1989; Townsend, 1990; Townsend \& Ashby, 1983; Townsend \& Schweickert, 1989).

The major topic examined in this essay is that of selfterminating processing, in which rapid search can cease as soon as the target is located, as opposed to exhaustive processing, in which search always extends through the entire available search set. As noted above, the issue of serial or parallel processing is difficult to resolve with the use of search paradigms in which the main independent variable is size of the memory or visual display set. Fortunately, the present study shows that the issue of selfterminating or exhaustive search is more impervious to analogous model-mimicking difficulties within such paradigms. We generalize and implement theoretical results of Townsend and Van Zandt (1990) to demonstrate that the behavior of mean RT under changes in the size of the search set can be used to distinguish between the two termination strategies. Furthermore, because of the limited range of predictable results by exhaustive models, our work suggests that exhaustive processing per se may rarely arise unless it is impelled by stringent conditions of an experiment (e.g., prohibitive penalties for missing a target). We will discuss our theoretical findings in the context of the portion of the rapid search literature that pertains to the self-terminating/exhaustive issue. We will then demonstrate the problematic nature of the exhaustive processing hypothesis by using data from two published studies.

\section{THEORETICAL AND EMPIRICAL BACKGROUND}

In Sternberg's (1966) seminal memory-search study, the size of the search set was varied, imposing different capacity demands on the processor responsible for comparisons between the target item and the search set. On half the trials, the search set contained a single target and on the remainder of the trials, the search set contained only distractors. Sternberg compared his data to the predictions made by what has come to be known as the standard serial model, as well as the class of unlimitedcapacity parallel models that assume independent processing on the items in the search set (see Townsend, 1974, or Townsend \& Ashby, 1983). Sternberg's 1966 Science paper also was apparently the first to address directly the issue of self-terminating and exhaustive processing by varying the size of the search set.

The standard serial processing hypothesis assumes that average processing times for all individual items are equal and independent of search set size, positions of items, and item identity. It predicts that the set-size functions (plots of mean RT as functions of the size of the search set) will be linear and increasing. If search is self-terminating as well, the positive set-size function will increase with a slope equal to half that of the negative set-size function. This is because the target will be found, on the average, half-way through the search, and processing can then terminate. If processing is exhaustive, however, then, assuming standard serial processing, there should be no difference between the slopes of the positive and negative set-size functions. Even when a target is present, processing will continue until all items in the search set are completed. A similar argument may be applied to the plots of position effects (mean RT under different target placements): if processing is serial and exhaustive, then target placement within the search set should have no effect on mean processing time and hence the position effects should be flat.

The set-size functions for Sternberg's (1966) experiment were quite linear and increasing, consistent with the standard serial predictions. These functions were not consistent with the increasing but curvilinear (negatively accelerated) set-size functions predicted by the exhaustive, unlimited-capacity, independent parallel models. Neither were they consistent with the flat mean RT predictions for positive trials made by the same type of parallel models when self-termination was assumed (e.g., Townsend, 1974). Furthermore, the positive and negative functions were parallel, and the placement of the target had little effect on the mean RTs. Comparing his data to the serial and parallel processing hypotheses, Sternberg found in favor of the standard serial, exhaustive processing model and continued to present its case in later papers (e.g., Sternberg, 1975).

An apparently cogent a priori argument against exhaustive processing is the seeming contradiction inherent in a limited-capacity processor, under time pressure, compelled to perform unnecessary operations after its job is finished. To justify why exhaustive processing might actually be beneficial in rapid search, Sternberg (1966) suggested that for search to self-terminate, not only would the system be required to make a comparison with each item in the search set, but it would also need to make a "stop/continue" decision after each comparison. If this decision required any additional amount of processing time, it might be more efficient to process the entire search 
set first, and then make a single "present" or "absent" decision at the end.

Since Sternberg published his classic work in 1966, some of the difficulties that can arise in testing hypotheses about mental processes have become apparent. First, it turned out that the classes of models that Sternberg tested were not as general as might have been hoped. For example, the standard serial model is one special case of the much larger class of serial models in which the time to process each item is a random variable that may or may not depend on set size, position, and so on. Second, the serial/parallel test was confounded by the variations in set size that changed the information processing load. Consequently, the increasing RT curves were functions not only of how processing capacity was distributed across the items in the search set (e.g., to one item at a time or all the items at once-the serial/parallel issue), but also of the more elemental variable of capacity itself (Townsend, 1974). Mathematical theorizing has demonstrated how each of these variables can contribute to mean RT (Townsend \& Ashby, 1983).

There are two additional empirical concerns. First, other tasks, such as forced-choice discrimination, should be used when possible in conjunction with search paradigms to provide converging evidence about the underlying processes (e.g., C. W. Eriksen et al., 1990; Sternberg, 1975; Townsend, 1990). Second, the use of mean RT alone may not always be sufficient; many studies have benefited from the use of additional statistics such as the RT variance and other dependent variables such as accuracy (e.g., Schneider \& Shiffrin, 1977; Townsend \& Ashby, 1983; Townsend \& Evans, 1983).

These theoretical and empirical obstacles are not unique to the rapid search paradigm, although it appears that search tasks have been more widely used than many other comparable paradigms in psychology. Its utility has moved beyond the serial/parallel question and into areas such as attentional control (e.g., Reeves \& Sperling, 1986) and processes in early vision (e.g., A. Treisman \& Gormican, 1988). In retrospect, it seems somewhat frustrating that so simple and useful a paradigm could not cleanly resolve the serial/parallel issue. It turns out that the situation is more propitious with regard to the self-terminating versus exhaustive processing question.

The first computer simulations and mathematical evaluations seemed to place the self-terminating/exhaustive question in the "unidentifiable" category along with the serial/parallel question. Theios, Smith, Haviland, Traupmann, and Moy (1973) developed a self-terminating model that made predictions compatible with data that previously were taken as evidence for exhaustive processing. Townsend and Roos (1973) showed how a general self-terminating model could produce equal-sloped positive and negative set-size functions and simultaneously produce position effects. Therefore, the equal-slope result could not falsify the self-terminating class of models, because either type of stopping rule could have led to that finding.
Further, Townsend (1974) demonstrated that exhaustive processing models could predict a certain range of position effects. Hence, the occurrence of position effects, not found by Sternberg (1966) but emerging in other studies, did not appear at the time, to be convincing evidence for self-termination. Theoretical results on selfterminating and exhaustive processing were extended by Ashby (1976). However, none of these earlier studies determined whether exhaustive models could predict strong position effects; that is, position effects as strong as those predictable by standard serial self-terminating models. Moreover, little theoretical information was available concerning the ability of general classes of exhaustive models to predict significant slope differences between the positive and negative set-size functions.

We have found that the self-terminating/exhaustive processing issue can be resolved for both serial and many parallel models (Townsend \& Van Zandt, 1990). Exhaustive processing models are unable to produce many common empirical results, because of the unrealistic capacity of the system that would be required to produce them. The present analysis is based on a theoretical approach in which the opposing psychological issues are embedded in general associated classes of mathematical models. This approach allows the derived conclusions to span many different specific models, each representing one of the competing principles, rather than being limited to a particular type of model. For instance, the exhaustive serial class contains, but is not limited to, the standard serial model or models based, say, on particular distributions, such as the gamma family. Because of this approach, the classes of models covered by our results are extremely large. If a very large class of models that embody a psychological principle, such as exhaustive processing, is unable to produce a certain empirical result, such as strong position effects, then the psychological principle on which the models are based is effectively falsified.

We examined the capacity requirements of these classes of models by examining the processing time distributions of the items in the search set. The processing time distributions of the items were permitted to vary according to display position, the processing order or path of search through the items, and the size of the search set. The way that a processing time distribution changes with set size reflects capacity effects on the processing channel. For instance, the processing time of an individual item might slow down, remain constant, or get faster with increasing load. Processes that slow down with increasing load are limited-capacity processes. Unlimited-capacity processes are unaffected by increases in processing load. Processes that increase efficiency by getting faster with increasing load are supercapacity processes. The exhaustive processing hypothesis was tested by evaluating these capacity changes.

As an example of how we proceeded, consider the serial class of models, which is very broad. The standard serial model proposed by Sternberg (1966) and others is a quite 
constrained member of this class. To generalize the standard serial model, it is necessary to relax the restriction that the processing times for all items be independently and identically distributed. In this way, the mean processing times can vary widely across all items in the search set. The capacity of the system is reflected in the mean processing times of individual nontarget or target items as load increases. For instance, if the mean target processing time decreases with increasing load, the target comparison process must be of supercapacity. If the mean nontarget processing time decreases with increasing load, the nontarget process must also be of supercapacity.

There has never been much, if any, evidence that human information processing in the usual kind of rapid search experiments could be of supercapacity in a reliable way. The very fact that RT goes up with load and that usually, errors increase as well, argues for limited-capacity processing. In the theoretical work reported here, it was assumed that supercapacity systems are generally unrealistic in the context of human information processing. We find that exhaustive models that are able to predict strong slope differences or position effects, whether serial or parallel, require consistent supercapacity processing ability. This finding renders the exhaustive processing hypothesis untenable for most empirical situations. The technical underpinnings of this work, including past results and present generalizations, are presented in the Appendix.

It now seems appropriate to review the relevant empirical literature relating to the exhaustive versus selfterminating issue, equipped with stronger theoretical tools than were available at the time of the initial studies. We will use these tools to collate results across related paradigms, examining mainly mean RT data, but attempting to take other dependent variables into account where possible. In the discussion to follow, we will outline the theoretical and empirical foundations of our conclusion that exhaustive processing is not feasible.

Several alternative methods of experimentation and analysis can be used to tease apart search-strategy issues. For example, RT variances can help distinguish between self-terminating and exhaustive processing within certain classes of models. This is because the variance of a selfterminating search in such models may be greater than the variance of an exhaustive search, due to the additional variance of the stopping time in the self-terminating case (Schneider \& Shiffrin, 1977; Townsend \& Ashby, 1983). Varying the number of targets presented in the search set is also a valuable experimental manipulation (the "redundant targets" design; see, e.g., Egeth, Folk, \& Mullin, 1988; Van der Heijden, 1975; Wolford, Wessel, \& Estes, 1968). Because the presence of multiple targets increases the probability of finding one target early in the search process, mean RT to detect a target should be faster when the target is repeated within the search set if a selfterminating strategy is being used. However, there is less evidence based on these alternative measures, so they will not be treated in as much detail. In much of the remainder of the paper, we will review the evidence using strong slope differences between the positive and negative setsize functions and using position effects.

\section{EVIDENCE FOR SELF-TERMINATING AND AGAINST EXHAUSTIVE PROCESSING}

The amount of research conducted with visual and memory search tasks is impressive, with many more or less minor variations in experimental procedures. We cannot hope to cover every detail in this paper, but we will attempt to broach those characteristics most important for the self-terminating/exhaustive question. This review will help to delineate the conditions under which slope differences and sizeable position effects occur, and, taken together with the theoretical results, suggest what kind of studies best test the two hypotheses. Furthermore, the pertinent experimental aspects may be useful in the building of future, more detailed models. Of course, the caveat should be borne in mind that the more different the experimental designs, the more risky the comparisons between them.

Several factors have been shown to influence RT in rapid search paradigms. Although these factors do not always bear directly on the issue of termination strategies, they produce some of the most robust findings in this field. Such factors include the obvious one of the presence of a target within the search set. Negative responses are typically slower than positive responses (Atkinson et al., 1969; Briggs \& Blaha, 1969; Burrows \& Okada, 1971; Egeth, Jonides, \& Wall, 1972; Pashler, 1987; Schneider \& Shiffrin, 1977; Townsend \& Roos, 1973; Yantis \& Jonides, 1984), although Sternberg's (1966) original memory search study indicated no statistical difference between positive and negative RTs. The processing load or set size is a major independent variable, as are the physical parameters of the stimulus items (e.g., Egeth, Virzi, \& Garbart, 1984; Ellis \& Chase, 1971; A. Treisman, Sykes, \& Gelade, 1977), the contextual or semantic characteristics of the stimulus items (e.g., Jonides \& Gleitman, 1972), the mapping of stimuli to responses (e.g., Shiffrin \& Schneider, 1977), and the frequency of presentation of the individual positive and negative stimuli (e.g., Krueger, 1970; Theios et al., 1973). The placement of the target within the search set also influences RT, as is evidenced by position effects (see, e.g., Baddeley \& Ecob, 1973).

Mean RT in rapid search tasks is often a linear, increasing function of set size (Bracey, 1969; Clifton \& Birenbaum, 1970; Conner, 1972; Ellis \& Chase, 1971; Hockley, 1984; Sternberg, 1966). However, concave functions are quite common (Briggs \& Swanson, 1970; Corballis, Kirby, \& Miller, 1972; Kristofferson, 1972b; Simpson, 1972; Swanson \& Briggs, 1969; M. Treisman \& Doctor, 1987), and it has been argued (Briggs, 1974) that a log function may provide a more adequate description of the data than a linear function. This shape is consistent 
with independent, unlimited-capacity, exhaustive parallel processing (e.g., Townsend \& Ashby, 1983).

Shiffrin (1988) suggests that the differences in the shape of the set-size functions may be due in part to differences in accuracy at different loads. The finding that error rates and RTs both increase with increasing load is common (Briggs \& Johnsen, 1972; Corballis et al., 1972; Schneider \& Shiffrin, 1977). If observers were to attempt to equalize their error rates across different set sizes by decreasing errors for large loads, the RTs for those loads would become slower, and therefore the set-size functions could become more linear and less concave. To stretch this hypothesis somewhat, if error rates are responsible for the linearity or nonlinearity of the set-size functions, perhaps an observer's position on the speed-accuracy tradeoff function could be shifted to produce slope differences as well. For example, a model could be devised in which errors increase for positive trials faster than for negative trials, in turn producing a decrease in positive RTs resulting in two-to-one slope ratios. We have been able to find no evidence for such performance shifts. Indeed, in some cases, a faster increase of errors for positive trials accompanies equal slopes (e.g., Klein \& Farrell, 1989).

An alternative explanation for curvilinear set-size functions was provided by Theios (1975). He showed that RT functions are linear only for set sizes smaller than six items. He suggested that these linear functions were an indication of the scanning of short-term memory. With set sizes of six or larger, Theios suggested that some of the items have to be retrieved from long-term memory, resulting in a ceiling or limit on the scanning time. Thus a mix between a relatively fast serial scan of short-term memory and a slower, but constant retrieval time from long-term memory results in a negatively accelerated increasing RT function (see Atkinson \& Juola, 1974, for data with large set sizes and negatively accelerated increasing RT functions).

Most of our theoretical results do not depend on the linearity of the set-size functions. Regardless of the shape of these functions, the capacity of the system that produced them is evident in the increases in RT arising from increases in set size. We may compare the change in positive and negative RTs when the set-size function increases in a linear way just as we may when one or both of the set-size functions is nonlinear.

\section{Slope Effects}

Many studies of visual and memory search report equalsloped set-size functions, either linear (e.g., Atkinson et al., 1969; Klatzky \& Smith, 1972; Kristofferson, 1972b; Sternberg, 1966) or curvilinear (e.g., Swanson \& Briggs, 1969; Townsend \& Roos, 1973). An equal number of studies have reported significant slope differences under several experimental manipulations (e.g., Clifton \& Birenbaum, 1970; Klatzky \& Atkinson, 1970; A. Treisman \& Gormican, 1988). Slope differences occur most frequently in visual search, often appearing under conditions where targets and nontargets are different from each other in some salient physical or contextual way (Jonides \& Gleitman, 1972; A. Treisman et al., 1977), and also when stimulus duration is restricted (Klein \& Farrell, 1989). In memory search, slope differences often appear in conjunction with steeper set-size functions (see Sternberg, 1975), suggesting that the differences arise from a more difficult comparison process. In agreement with this interpretation, slope differences become more prominent when the load and hence the complexity of the task is increased in visual/memory search (Schneider \& Shiffrin, 1977). Some varieties of display presentation also induce slope differences in memory search, as does the amount of practice with stimuli consistently mapped to the target set (Kristofferson, 1972a). Memory search most often yields parallel set-size functions, whereas visual search is more likely to yield significant slope differences. Although this might suggest that the processes operating in each paradigm are different, this aspect is not crucial for our discussion.

Several alternatives to the search and comparison constructs have been suggested, the most notable of which are those models that assume "direct access" to the items in memory search sets (Baddeley \& Ecob, 1973; Corballis et al., 1972). Presentation of the target item gives rise to an internal representation that has some "trace strength." The observer responds positively or negatively, depending on the magnitude of this trace strength. More theoretical research on direct access models is needed in this context, but it appears that the direct access hypothesis may be difficult to test against parallel process models (see also Theios \& Muise, 1977). Let us agree for present purposes to refer to search as an effortful process that includes serial and parallel models that possess either limited or unlimited capacity at the level of the individual item. As noted, unlimited capacity implies that the average individual processing time does not increase as the load is increased, and limited-capacity processing implies that the average individual processing time may increase as the input load grows.

The argument that effortful search takes place is most easily made when the set-size function increases with increasing load. When the set-size function is flat, other alternatives such as direct access must be considered. Nevertheless, it must be remembered that self-terminating, unlimited-capacity parallel search can readily predict flat set-size functions on positive trials. In any event, whether processing consists of self-terminating parallel search or direct access, flat positive set-size functions occur with consistent mapping procedures (discussed below), and in visual search they are often associated with perceptual pop-out. When such effects occur, it is sometimes proposed that no effort or capacity, and therefore no search in the present sense, is required. Because of the ability of unlimited-capacity, self-terminating parallel models to predict flat postive set-size functions, it may again be difficult to distinguish the former from something like, say, an automatic direct access, high-strength process. Some additional evidence, perhaps physiological, may support the idea of a truly "effortless" activity, as suggested be- 
low. The important point here is that if the data include both positive and negative RTs, the query as to the exhaustive versus self-terminating issues may legitimately be raised. Certainly, few would oppose the concept that automatic or direct access processes have little resemblance to effortful, capacity-consuming exhaustive processes. Of course, where negative set-size data are not gathered, the issue may be moot. However, it is of interest to take note where flat positive set-size functions and pop-out effects are most likely to be exhibited.

Consistent mapping. Rapid search paradigms can use either a consistent or a varied mapping procedure. With consistent mapping, stimuli that appear as targets on some trials never appear as nontargets on others. That is, a portion of the stimulus set always requires a positive response, and the remaining portion is always used as nontargets. After enough exposure to the stimulus set, observers' positive RTs are relatively fast and invariant across set size. It is not surprising, then, that search performance under consistent mapping is extremely sensitive to the amount of practice that the observers receive (Kristofferson, 1972a; Schneider \& Shiffrin, 1977). Varied mapping procedures show no such decrease in positive slope, although the overall RTs decrease (Schneider \& Shiffrin, 1977).

Strayer and Kramer (1990) examined consistent and varied mapping procedures by using a dual-task paradigm and event-related potentials (ERPs). They found that secondary task performance was unaffected by the load of a primary consistent mapping memory search task, although performance on the secondary task was deleteriously affected by increasing load in a primary varied mapping memory task. They also found that the amplitude of the P300 was systematically influenced by the load in varied mapping but not in consistent mapping memory search. The P300 is that component of the ERP commonly associated with attention-demanding tasks. This suggests that performance on positive trials in the consistent mapping memory search task requires little effort and may not require a comparison between the target and the accompanying distractors. Nevertheless, it is still possible that such physiological effects (or absence thereof) might be associated with an unlimited-capacity and selfterminating parallel process.

Perceptual pop-out. In visual search, targets that differ from nontargets in some salient physical way often "pop out," and the presence of the nontargets apparently has no effect on the observer's ability to perceive the target. Targets that differ from nontargets in color (Carter, 1982; Egeth et al., 1984; Green \& Anderson, 1956; A. Treisman et al., 1977), or by some other obvious physical property such as size or form (Beck, 1967; Ellis \& Chase, 1971; Julesz, 1981; Navon, 1977; A. Treisman \& Gormican, 1988), produce flat positive set-size functions, as long as the display can be processed in a single glance (e.g., Pashler, 1987). It has been hypothesized that in these cases there is no search as such taking place (Julesz, 1981). Rather, items are preattentively segregated by their values on a particular feature dimension. If a single target differs from the distractors on that dimension, it should be readily discriminable from the background of distractors.

Pop-out effects may also occur in conditions where the target differs from the nontargets in context or semantic content such as letters versus digits. Sperling, Budiansky, Spivak, and Johnson (1971) demonstrated that scanning rates for the presence of a numeral among letters, as calculated from the number of correct responses with different rates of display presentation, were independent of the number of letters to be scanned. Jonides and Gleitman (1972) also showed that search time for the character " $O$ " was independent of the number of digit (letter) distractors in the display, if " $O$ " ' was defined to be a letter (digit). Although Duncan (1983) and Krueger (1984) convincingly demonstrated that this effect arises from the featural differences between letters and digits, Biederman and his colleagues (e.g., Biederman, Rabinowitz, \& Glass, 1974) have confirmed that in search through scenes, context and semantic content are important factors. Although the exhaustive versus self-terminating issue is usually not the main focus of attention in such studies, from one point of view, the pop-out effect with its implications for unlimited capacity parallel or effortless direct access may be the ultimate in self-terminating behavior.

Increasing set-size functions and slope differences. We will now confine our attention to cases in which the set-size function is increasing, under the hypothesis that increases in RT reflect the influence of a search. That is, we assume that each item in the search set has devoted to it some amount of attentional resource; the comparison process is effortful. Strayer and Kramer's (1990) demonstration, just discussed, suggests that varied mapping memory search requires a systematic processing of nontargets. Although in memory search it has been debated whether a search per se is occurring (Shulman, 1990; Stadler \& Logan, 1989), the search construct is much employed (e.g., Fisk \& Ackerman, 1988; Johnson \& Carnot, 1990; Wijers, Mulder, Okita, \& Mulder, 1989).

In visual search, the capacity-demanding search assumption has not been much debated; when it was, consistent mapping was involved (Logan, 1976). To provide converging evidence for a comparison process in the spirit of Strayer and Kramer's (1990) study, Madden and Allen (1989) used a dual-task paradigm with visual search. They too found that performance of the secondary task suffered as load increased in the primary visual search task. Thus, varied mapping visual and memory search demand attention, and this attention is somehow devoted to processing the items in the search set. In turn, this process takes time.

We mentioned earlier that parallel set-size functions most often appear in the context of memory search, whereas slope differences most often appear in visual search. We also mentioned that memory and visual search differ beyond the obvious discrepancies between memory load and display size. Perhaps they differ in terms of self-terminating or exhaustive search strategies. Recall, however, that slope differences do arise in memory 
search (Clifton \& Birenbaum, 1970; Klatzky \& Atkinson, 1970), just as parallel set-size functions have been observed in visual search (Atkinson et al., 1969; Townsend \& Roos, 1973). Any theory devised to explain the parallel functions in memory or visual search must be flexible enough to also accommodate the studies in which slope differences arise. If the conditions under which slope differences are observed are clear, such theorizing may be simplified.

Some slope differences may arise simply as a function of the physical nature of the display. For example, a visual display may be presented so that an observer is encouraged to search in a particular order, such as left-to-right or topto-bottom, and hence promote a self-terminating search. Hockley (1984) presented vertical displays of letters in such a way that the topmost letter appeared in the same position as the fixation point. When such displays were used in a visual search task, two-to-one slope ratios were found. However, when Hockley used the same displays in a memory search task, the set-size functions were parallel. Townsend and Roos (1973), using horizontal displays, explicitly instructed their subjects to "scan" the display from left to right. The observation of position effects assured that the subjects were indeed scanning from left to right, but they observed no significant slope differences for either the visual or the memory search task.

Some of the most interesting data on slope differences come from mixed visual/memory search experiments, where interactions of memory load with display size can be observed. Nickerson (1966) performed the first of these studies. He presented observers with a memory set of one, two, or four letters, followed by a visual display of one, two, or four letters. When the memory load consisted of a single letter, no slope differences were observed when RTs were plotted as a function of display size. With memory loads of two and four, the slope of the positive function became half that of the negative function.

Burrows and Murdock (1969) conducted a similar study, in which the memory load varied from one to three digits, and the display size varied from three to six. Unlike Nickerson's (1966) findings, two-to-one slope ratios were apparent for all memory loads. This difference is most likely due to the different amounts of practice that the observers received in the two experiments. Nickerson's subjects may have performed as few as 128 trials, whereas Burrows and Murdock's subjects performed 2,880.

Slope differences have since been replicated many times in visual/memory search (see, e.g., Briggs \& Johnsen, 1972; Fisk \& Ackerman, 1988; Schneider \& Shiffrin, 1977). Shiffrin (1988) has suggested that differences in slope appear when the load is increased or when the task becomes more complex. This is consistent with Sternberg's (1975) arguments, and his observation that two-to-one slope ratios in memory search usually occur in conjunction with increased slopes.

A common suggestion has been that when set-size functions are parallel, search is exhaustive, and that slope differences arise when processing shifts to the more efficient terminating strategy (e.g., Houck \& Hoffman, 1986). The idea is that self-termination makes its appearance after sufficient practice or when the processing load is excessive. An alternative hypothesis is that self-terminating processes are the rule, and that they are less visible under some conditions. This is exactly what our theoretical findings suggest to us, as will be seen below.

\section{Slope Predictions}

We have demonstrated that large classes of serial and parallel exhaustive models cannot produce slope differences without supercapacity processing or without predicting empirical results never before observed. For serial models, even the most general limited- or unlimitedcapacity serial exhaustive models cannot predict a negative to positive slope ratio of greater than $n$ to $n-1$, where $n$ represents the set size (see Proposition 1, Appendix). Since, for $n>2, n /(n-1)$ is closer to 1 than the $2: 1$ ratio associated with the standard serial self-terminating model, the conclusion is very strong indeed. For instance, if $n=6$, any ratio greater than $6 / 5=1.2$ falsifies serial exhaustive models. In light of that result, reliable empirical findings of a ratio of 2:1 or greater offer extremely solid evidence against serial exhaustive processing. The results from a number of both visual and memory search experiments, and most of the results from visual/memory search experiments, bolster this evidence.

For parallel models, we showed that a fairly large class of parallel exhaustive models are incapable of predicting a slope ratio greater than one (see Propositions 3 and 4, Appendix). Proposition 3 states that for unlimited-capacity models, any positive to negative slope ratio greater than one forces the positive RTs to be slower than the negative RTs. The reverse is empirically true; positive RTs are almost always faster than or equal to negative RTs. Proposition 4 hypothesizes that the negative process is of unlimited capacity and the positive and negative processing times are equal for $n=1$, though they may differ for larger $n$. In this case, any slope differences imply that the target process is of supercapacity. These theorems are confined to independent channels, and the conclusions with regard to limited-capacity parallel systems are somewhat weaker (Townsend \& Van Zandt, 1990, pp. 484-485). Nevertheless, they suffice to rule many exhaustive parallel models for a sizeable number of experiments, including those obeying the important classical standard serial self-terminating prediction of the 2:1 ratio.

Because slope differences are not exclusive to any one experimental paradigm, the system that produces them must be flexible enough to produce equal-sloped set-size functions as well. Self-terminating models can handily produce the wide range of slope differences we have discussed here. Exhaustive models, as we have demonstrated, cannot. We now turn to an examination of position effects in rapid search, and we will see that the prospects for the exhaustive processing hypothesis grow even more dire.

\section{Position Effects}

When position effects appear, they can take several forms. RT has been observed to increase with target place- 
ment, as a primacy effect (Atkinson et al., 1969; Harris, Shaw, \& Altom, 1985; Hockley, 1984; Klatzky \& Atkinson, 1970; Klatzky, Juola, \& Atkinson, 1971; Klatzky \& Smith, 1972; Townsend \& Roos, 1973), and to decrease with target placement, as a recency effect (Clifton $\& \mathrm{Bi}$ renbaum, 1970; Corballis, 1967; Forrin \& Cunningham, 1973). Simultaneous primacy and recency effects have also been observed, producing concave position effects (Burrows \& Okada, 1971; Corballis et al., 1972).

The experimental conditions under which position effects appear are easier to identify than those that produce significant slope differences. Position effects generally appear when a specific processing order of the stimuli is fostered by the presentation conditions: when the items in the search set are temporally distinct in memory search (e.g., Clifton \& Birenbaum, 1970; Forrin \& Cunningham, 1973), or when the observer is induced either by the nature of the display or by the experimenter's instructions to process the search set in a certain order (Harris et al., 1985; Hockley, 1984; Townsend \& Roos, 1973). The term processing order is not meant to imply serial processing, but rather the ordering of finishing times for the items in the display.

Neisser (1964) conducted a seminal visual search study in which observers were required to scan lists of 25 sixletter strings for a target letter. He found very strong linear position effects. Undeniably, the observer was terminating the search soon after the target was recognized. Because the list was so long, exhaustive processing was clearly inappropriate; mean RTs ranged upward of $20 \mathrm{sec}$ when the target occurred late in the list. Most visual and memory search studies since then have been done with much smaller search sets and a greater emphasis on speed.

Two experiments, one performed by Atkinson et al. (1969) and the other by Townsend and Roos (1973), demonstrate that position effects can be very sensitive to the instructions given to the observer. Townsend and Roos presented observers with horizontal arrays of letters varying in length from one to five that were centered on the presentation screen. In both visual and memory search, observers were instructed to scan the displays from left to right. They found strong primacy (left-to-right) position effects in the visual search task, and moderate primacy effects in the memory search task. Atkinson et al. presented observers with horizontal arrays of letters varying in length from one to five, but did not instruct them to scan in any order. The array was always centered on the screen, as in the Townsend and Roos study. Although RT was affected by target placement, no significant interaction of target placement on RT was observed; no evidence of any processing order was observed in recency or primacy effects, as was seen in the Townsend and Roos data.

There is one other difference between the Atkinson et al. (1969) study and the Townsend and Roos (1973) study, besides the experimenters' instructions, that could have contributed to the attenuation of position effects. The visual angles of the displays used by Atkinson et al. were half those of the displays used by Townsend and Roos $\left(2.2^{\circ}\right.$ vs. $5.5^{\circ}$ for the largest display sizes, respectively).
Display durations for both studies were $400 \mathrm{msec}$, which may have allowed the observers to make eye movements during presentation, which in turn could have contributed to the Townsend and Roos position effects. However, Klein and Farrell (1989) have demonstrated that the contribution of eye movements to search performance is probably minimal. They compared performance in a standard visual search task with performance where eye position was monitored and trials with eye movements were discarded. There was no difference in the patterns of mean RTs between the two conditions. Thus, the instructions to the observer, rather than the width of the display, were the most likely source of the position effects in the Townsend and Roos (1973) study.

When the shape of the display is such that it might easily invoke a certain processing order upon the display items, such as left to right for horizontal arrays or top to bottom for vertical arrays, the position of the target may have a strong effect on RT. A processing order may also be induced by the position of a fixation point relative to the display items, and the resulting direction that the eye movements take over the array (e.g., Rayner \& Fisher, 1987). A fixation point placed at an end of array may cause items at that end to be processed before the items farthest from fixation.

Harris et al. (1985) also conducted a visual search study in which observers were presented with horizontal arrays of 10 letters, and instructed to scan from left to right. Such a scanning process was encouraged by presenting the displays so that the leftmost letter of the display appeared to the right of the fixation point. Scanning could not possibly have occurred through overt eye movements, however, because the displays were only presented for $175 \mathrm{msec}$. With this procedure, dramatic position effects were obtained. Hockley (1984) conducted a visual and memory search study (mentioned earlier) in which observers were presented with vertical arrays of letters varying in length from three to six. The displays were presented in such a way that the topmost item was located in the same position as the fixation point. He found strong primacy (top-to-bottom) effects in the visual search task, but no effect of target position in the memory search task. His observers were not provided with instructions to process from top to bottom, although the position of the array in relation to the fixation point probably induced such a processing order.

The primacy effects found in these studies support the hypothesis that finishing times of display items can be induced to occur in a preferred order, either by the relative placement of fixation points, or by the instructions from the experimenter. Although these studies have been primarily visual search paradigms, memory search paradigms, in which the order of the scanning or comparison process is much less certain, also show position effects. These position effects are quite strong when the search set is displayed sequentially, as was done in most early memory search studies (Corballis, 1967; Forrin \& Cunningham, 1973; Klatzky \& Atkinson, 1970), particularly when the time that elapses between the presentation of 
the last item of the search set and the presentation of the target is short (Clifton \& Birenbaum, 1970). Consistent with our previous discussion, a sequential display presentation imposes an order on the items in the search set through the temporal separation between them.

\section{Position Effect Predictions}

Strong position effects, then, are pervasive in both visual and memory search. As noted above, we know that exhaustive models are capable of producing some degree of positional variation (see, e.g., Ashby, 1976; Townsend, 1974). It was therefore of interest to learn whether the effects predicted by a standard serial exhaustive model with a single processing path could be predicted by any exhaustive model. By a single processing path, we mean that the serial scan always processes the various positions in exactly the same order on each trial, as, for example, from left to right. We term this prediction strong position effects, and a mathematical definition is provided in the Appendix.

Serial exhaustive models cannot predict strong position effects without also assuming highly supercapacity processing (see Proposition 2, Appendix). With regard to parallel models, the theorems from Townsend and Van Zandt (1990) were not so general as the serial results. Only independent exponential models were shown to be unable to predict strong position effects (see Proposition 5, Appendix). The slope of the effects that this model can produce is very limited, and for large set sizes showing no slope differences between linear set-size functions, the position effect function must be flat (see Proposition 8, Appendix). Our review of the rapid search literature, taken together with our theoretical findings, suggests that exhaustive search strategies are rarely used. We now turn to a brief consideration of other experimental designs and the use of the variance statistic.

\section{Redundant Targets and Reaction Time Variance}

A search or detection paradigm in which the observer is presented with the same target more than once within the search set, or with targets that require the same (positive) response, has been called the redundant targets paradigm (Baddeley \& Ecob, 1973; Biederman \& Checkosky, 1970; Bjork \& Estes, 1971; Estes, 1972; Estes \& Taylor, 1964; Snodgrass \& Townsend, 1980; Van der Heijden, La Heij, \& Boer, 1983; Van der Heijden \& Menckenberg, 1974; Wolford et al., 1968). Mean RT is found to decrease as the number of redundant targets increases; this is termed a redundancy gain. These results are inconsistent with a standard serial, exhaustive processing hypothesis that postulates equal processing times for all items regardless of their status as target or nontarget.

If it is assumed that targets are processed faster than nontargets, however, these results in isolation could possibly be accommodated by an exhaustive processing model, in some of the paradigms. In some studies, the set size is fixed and the number of targets placed among the distractors on positive trials is varied (e.g., Wolford et al., 1968). Here, if positive matches are faster than mismatches, one expects mean RT to decrease with the number of targets. However, in some studies, the set size is varied, and displays on every positive trial are composed of the set of all targets (see, e.g., Egeth et al., 1988). Decreasing mean RT as the positive set size is varied cannot be explained by fast matches without also assuming supercapacity processing.

The hypothesis that redundancy gain may be an artifact due to an observer's "positional preferences," rather than any termination strategy, has also been examined (Biederman \& Checkosky, 1970; Mullin, Egeth, \& Mordkoff, 1988; Van der Heijden et al., 1983). If an observer attends preferentially to a given position within the display, the time to respond to a target in that display could be considerably faster when redundant targets are present because of the increased probability that a target will be located in the preferred position. Note that the effect of a positional preference on RT is still suggestive of a terminating process; the search is over sooner if the target falls in a preferred position (i.e., it is processed first).

Further evidence concerning the terminating rule can be found by examining the RT variance as a function of increasing load. The time to respond to the presence or absence of a target within the search set is a function of the number of comparisons to be made between the target and the items in the search set. Likewise, the variance of the response time is a function of the variance of the comparison times, and in addition, the point at which the process stops. Exhaustive processing strategies have no extra variance component representing when the target was found, or the search terminated, since the stopping point is the same, regardless of the presence or absence of a target. Terminating strategies, on the other hand, can show increasing positive RT variance relative to negative RT variance with increased load, because of the increased number of possible stopping points in the search. Most theoretical work on this topic has so far been done on the standard serial model (Schneider \& Shiffrin, 1977; Townsend \& Ashby, 1983). Parallel models that perfectly mimic the standard serial model, such as the capacity reallocation model (e.g., Townsend, 1974), also obviously make the same variance prediction.

However, it appears on the basis of informal calculations that some self-terminating parallel models may not predict such a strong divergence of the positive and negative variances. Also, in principle, exhaustive models can predict some difference in variances between positive and negative search because the distribution of the positive match can differ from that for negative matches. It does seem unlikely that this factor would permit a very large divergence of variance functions. More theoretical work on these questions is needed.

Although RT variances are rarely reported, Schneider and Shiffrin (1977) presented variance data that were consistent with a terminating process. Using varied-mapping and consistent-mapping visual search tasks, they demonstrated that the RT variances of the positive process increased more rapidly than the RT variances of the nega- 
tive process in the varied-mapping task, whereas the consistent-mapping task showed no such differences between positive and negative RT variances. Besides providing support for the self-terminating hypothesis, these results also support the notion that consistent-mapping tasks do not require the completion of a comparison process, whereas varied-mapping tasks require an attentiondemanding search.

\section{Summary of Empirical Review}

We have discussed a wide range of empirical findings in rapid search tasks. First, slope differences between positive and negative set-size functions pervade the visual, memory, and visual/memory search literature. These slope differences commonly appear as two-to-one slope ratios of the negative to positive function. These results alone provide strong support against the existence of an exhaustive search. Second, position effects are also widely observed, usually as shorter mean RTs when a target falls in the extreme positions (spatial or temporal) of the search set. Although some exhaustive processing models can produce a limited range of position effects, these findings are generally not supportive of such a search strategy. The observations that redundant targets within the search set often produce decreased mean RTs, and that positive RT variance appears to increase with load more rapidly than negative RT variance, serve to make the case even more problematic for the exhaustive processing notion. However, despite the fact that most studies show one or more findings insupportable of exhaustive processing, it is interesting to attempt to fit an exhaustive model that permits considerable generality in its assumptions about rates of processing to actual data. This task is carried out in the following section.

\section{AN EMPIRICAL APPLICATION}

To make clear the preceding argument, we now present a concrete application of our results. What follows is an examination of two studies, one that shows significant slope differences and one that does not. We chose the studies by Hockley (1984) and Townsend and Roos (1973) for our demonstration, because both studies examined visual and memory search and both studies used variedmapping paradigms. The Townsend and Roos study showed no significant slope differences for either visual or memory search, but showed sizable position effects for both. From the previous discussion, we must predict that no serial exhaustive model can fit these data. The Hockley study exhibited effects consistent with standard serial self-terminating processing for visual search (which should implicate poor fits for exhaustive models) and effects consistent with standard serial exhaustive processing for memory search.

By the previously stated theoretical results, serial exhaustive models are qualitatively ruled out by either the slope ratios or position effects in all but Hockley's (1984) memory search experiment. Parallel, limited-capacity models could possibly fit. We will examine the conditions that must hold for a parallel, independent exponential, exhaustive processing model to be able to fit these four sets of data (Townsend \& Roos, 1973, and Hockley, 1984, visual and memory search). We will use the conditions stated in Proposition 6 (see the Appendix), which do not make any assumptions about the capacity of the system and thus enhance the capability of this model to fit these data. The reader is referred to Townsend and Ashby (1983) for more details on notation and general modeling principles applied here, although the present results are new.

Let $n$ represent the size of the search set, and let $v_{i}^{+}(n)$ be the processing rate for the target in position $i$. Also let $v^{-}(n)$ be the processing rate for every nontarget. We will assume for simplicity's sake that the position effect functions are not significantly different from linear. The positive set-size functions have slope $s$, and for each load $n$, the position effect function has slope $p(n)$.

It can be shown that the requirements that must be met to insure the existence of the rates $v_{i}^{\dagger}(n)$ are first that

$$
s n-\left(\frac{n-1}{2}\right)|p(n)|>\frac{\sum_{i=1}^{n-1}(1 / i)}{v^{-}(n)},
$$

and second that

$$
s n>\frac{\sum_{i=1}^{n-1}(1 / i)}{v^{-}(n)} .
$$

Inequality 1 reflects the condition that must hold to ensure the existence of rates $v_{i}^{+}(n)$ that can produce the observed position effects. Inequality 2 reflects the condition that must hold to ensure the existence of any rate $v_{i}^{+}(n)$ that can produce the observed mean processing time. Note that if Inequality 1 is satisfied, Inequality 2 must be also. If both of these inequalities hold, it makes sense to solve for $v_{i}^{*}(n)$ and fit the model. If not, there is no need to continue; no rate greater than zero exists that can produce the pattern of mean RTs.

To fit the model to the Hockley (1984) and Townsend and Roos (1973) data, we first calculated regression lines through the set-size and position effect functions (interpolating the position effects for Hockley's data from the graphs given in his paper). The data were generally linear, and this gave clean estimates of the slopes of these functions. From these slope estimates, we then calculated the negative rates for each load and the values needed for one to check the inequalities above. The regression equations for the set-size functions and position effects are given in Table 1 for the Hockley (1984) and Townsend and Roos (1973) data.

Tables 2 and 3 show the calculations used to test Inequalities 1 and 2. The calculations for Hockley's (1984) experiments are shown in Table 2, and the calculations for Townsend and Roos's (1973) experiments are shown in Table 3. The first column of each table is the set size $n$. The second column of each table is the mean process- 
Table 1

Regression Lines for Set-Size Functions and Position Effects

for the Visual and Memory Search Experiments

of Hockley (1984) and Townsend and Roos (1973)

\begin{tabular}{|c|c|c|}
\hline & Hockley (1984) & Townsend and Roos (1973) \\
\hline Memory set-size functions & $\begin{array}{l}\mathrm{RT}^{+}(n)=41.5 n+488 \\
\mathrm{RT}^{-}(n)=48.9 n+535\end{array}$ & $\begin{array}{l}\mathrm{RT}^{+}(n)=26.5 n+599 \\
\mathrm{RT}^{-}(n)=23.8 n+544\end{array}$ \\
\hline Position effect functions & $\begin{array}{l}\operatorname{RT}_{3}^{*}(i)=14.5 i+579 \\
\operatorname{RT}_{4}^{*}(i)=-15.0 i+579 \\
\operatorname{RT}_{3}^{+}(i)=6.5 i+673 \\
\operatorname{RT}_{6}^{*}(i)=-4.4 i+752\end{array}$ & $\begin{array}{l}\mathbf{R T}_{\mathbf{i}}^{+}(i)=36.2 i+545 \\
\operatorname{RT}_{3}^{+}(i)=46.8 i+540 \\
\operatorname{RT}_{4}^{+}(i)=18.9 i+601 \\
\operatorname{RT}_{3}^{+}(i)=13.9 i+604\end{array}$ \\
\hline Visual set-size functions & $\begin{array}{l}\mathrm{RT}^{+}(n)=58.5 n+431 \\
\mathrm{RT}^{-}(n)=111.7 n+330\end{array}$ & $\begin{array}{l}\mathrm{RT}^{+}(n)=22.8 n+578 \\
\mathrm{RT}^{-}(n)=15.3 n+654\end{array}$ \\
\hline Position effect functions & $\begin{array}{l}\mathrm{RT}_{3}^{*}(i)=12.5 i+583 \\
\mathrm{RT}_{4}(i)=26.0 i+595 \\
\mathrm{RT}_{5}^{*}(i)=49.0 i+559 \\
\mathrm{RT}_{6}^{*}(i)=50.6 i+616\end{array}$ & $\begin{array}{l}\operatorname{RT}_{2}^{+}(i)=28.4 i+579 \\
\operatorname{RT}_{\mathbf{3}}^{*}(i)=45.1 i+555 \\
\operatorname{RT}_{4}^{*}(i)=24.3 i+609 \\
\operatorname{RT}_{\mathbf{3}}^{*}(i)=14.7 i+647\end{array}$ \\
\hline
\end{tabular}

Note- $\mathrm{RT}^{+}(n)$ and $\mathrm{RT}^{-}(n)$ indicate the positive and negative set-size functions, respectively. $\mathrm{RT}_{j}^{+}(i)$ indicates the position effects for a search set of $j$ items.

Table 2

Testing the Conditions Under Which Positive Processing Rates Exist to Produce the Observed RT Patterns in Hockley's (1984) Visual and Memory Search Study

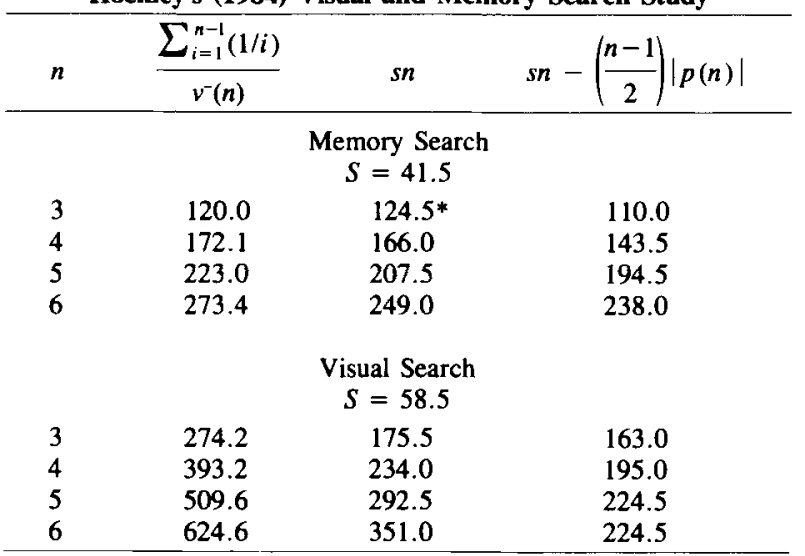

*Points for which rates exist.

Table 3

Testing the Conditions Under Which Positive Processing

Rates Exist to Produce the Observed RT Patterns in Townsend and Roos's (1973) Visual and Memory Search Study

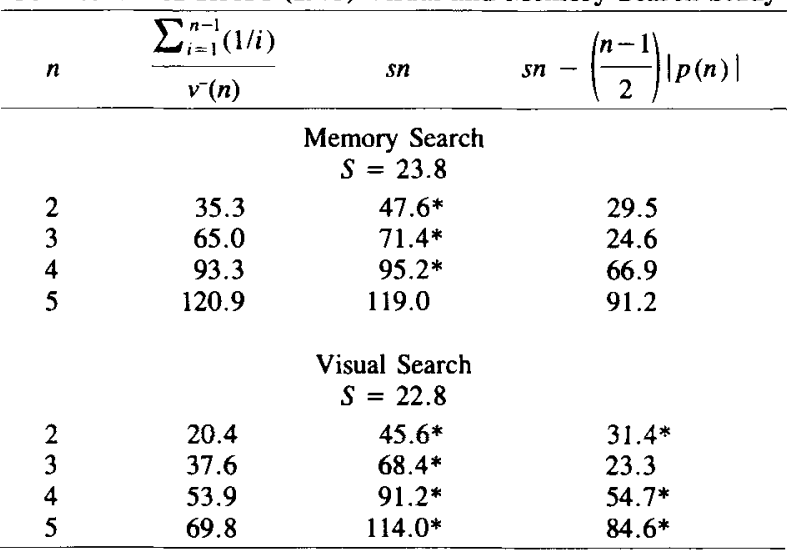

*Points for which rates exist. ing time for the $n-1$ nontarget items. The third column gives the critical values for Inequality 2 ; the values in this column must be greater than the values in the second column, to assure the existence of target processing rates that will produce the observed set-size function. The fourth column gives the critical values for Inequality 1 ; the values in this column must be greater than the values in the second column to assure the existence of target processing rates that will produce the observed position effects. Values that preserve the inequalities-that is, conditions in which positive target processing rates existare underlined.

The parallel exhaustive model fared extremely poorly with Hockley's (1984) data, even though the memory study produced seemingly classic serial exhaustive results. This is because the positive slope is less than the negative slope: a slope ratio of $48.9 / 41.5 \approx 1.18$. Even though this ratio is extremely close to one, it is sufficient to prevent the existence of any positive processing rates that can produce the mean processing time. Given that even the weak Inequality 2 associated with mean reaction times is falsified, the strong Inequality 1 associated with position effects is violated a fortiori. Hockley's visual search study, with a pronounced two-to-one slope ratio and strong position effects, violated both conditions at all data points.

The parallel exhaustive model fared quite a bit better with the Townsend and Roos (1973) data. For the memory search experiment, Inequality 1 was violated for all position effect functions, but weak Inequality 2 held for all but the largest memory load. For the visual search experiment, the only violation was for Inequality 1 at the search set of size three. The exhaustive model did much better for the visual search study because the positive setsize function actually increased more rapidly than the negative set-size function. Even so, there are no positive rates that can account for the position effects at the search set of size three.

Notice that none of the preceding computations limited the capacity of the parallel exhaustive system. In most 
cases, even the most supercapacity system could not have produced the observed RT patterns; a target process with an infinite rate could not have been fast enough. A limitedcapacity parallel exhaustive model could have produced the Townsend and Roos (1973) visual search results at the level of the set-size functions. It could not have simultaneously produced the observed position effects. The most striking result from this application is that for Hockley's (1984) memory search study, with parallel set-size functions and relatively flat position effects, the parallel exhaustive model was unable to account for the data. If the model could have fit one set of data, it should have been that one. The sensitivity of the model to a 1.18 slope ratio demonstrates conclusively that the exhaustive search hypothesis cannot be generally valid.

\section{SUMMARY AND DISCUSSION}

Work by Theios et al. (1973) and Townsend (1974) has shown that self-terminating models (both serial and parallel) can predict arbitrary slope ratios between the negative and positive set-size functions. These models can also predict arbitrary position effects, ranging from strong to flat. Therefore, self-terminating models can accommodate all of the diverse rapid search findings observed over the past 25 years. We have observed that, under conditions where effortful search could be implicated, the findings of slope differences and position effects were not peculiar to either the memory or the visual search paradigm. Although slope differences are more commonly observed in visual search, they are sometimes observed in memory search. Parallel set-size functions are also common to both. Position effects occur in most experiments; only rarely are they not observed.

Unequal slopes and position effects are not impossible in principle in exhaustive processing, if there are rate differences between the match and mismatch processes. However, our recent mathematical investigations have proven that both parallel and serial exhaustive predictions for slope ratios are very constrained. Similarly, strong position effects cannot be attained by either class of exhaustive processes. Thus, exhaustive processes cannot produce the differences between positive and negative setsize functions, or the varied range of position effects that predominate in the experimental search studies reviewed here. This result was emphasized in a failed attempt to fit an exhaustive model to data from two published search studies. The findings that mean RT often decreases with the number of redundant targets and that positive RT variances appear to increase relative to negative variances further contribute to the evidence against exhaustive processing.

For reasons of parsimony, we argue that self-terminating processes are responsible for most of the previously recounted effects. Various experimental procedures could have the effect of changing the rate at which individual comparisons, especially among matches and mismatches, are made, and so account for the range of findings that we have presented. The experimental arrangements that appear to encourage slope ratios of two to one or greater, or sizeable position effects, may be interpreted as simply allowing the self-terminating process to exhibit itself through visible means. When set-size function slopes are equal, or position functions are flat, the underlying selfterminating system may just not be so obvious.

An alternative viewpoint is that observers could be terminating search in the studies in which significant slope or position effects occur, and they could be searching exhaustively in those without such effects. Proctor and Healy (1987) presented evidence that could have suggested that, in a same-different matching task, an observer's processing strategy changes depending on the task demands. When observers were required to respond "same" only when the items in the two arrays were physically the same and in the same positions (the order-relevant task), position effects were different from those observed when the position of the stimulus items was irrelevant (the orderirrelevant task). It seemed plausible that observers were switching between exhaustive (in the order-irrelevant) and terminating (in the order-relevant) comparison strategies.

More recently, Proctor, Healy, and Van Zandt (1991) clarified these findings. They conducted a series of experiments with the order-relevant and order-irrelevant matching tasks, in which the probability of the location of a mismatching item varied across display positions, and the spacing between the display items was varied. These manipulations were designed to encourage specific comparison strategies. Surprisingly, the RT pattern remained unchanged over conditions, suggesting that any differences between the order-relevant and order-irrelevant tasks were due to the different response requirements in the two tasks. Because the observers seemed unable to use information about the display conditions to optimize their performance, these results suggest that observers may have less control over central comparison strategies than previously thought.

Eriksen and his colleagues have demonstrated further that strategic control is possibly very limited. Even if the necessity of "search" is eliminated by presenting the target in the same position on each trial or by cuing, some processing of nontarget items is unavoidable (Colegate, Hoffman, \& C. W. Eriksen, 1973; C. W. Eriksen \& Collins, 1969; C. W. Eriksen \& Hoffman, 1972; C. W. Eriksen \& Rohrbaugh, 1970), and there is a lower limit on the smallest number of display items that can be processed (B. A. Eriksen \& C. W. Eriksen, 1974; C. W. Eriksen, Hamlin, \& Daye, 1973). Even when the target is spatially separated from the nontargets, the presence of the nontargets affects detection performance (Banks \& Prinzmetal, 1976; Gatti \& Egeth, 1978).

The fact that some needless nontarget processing must occur around the area of the target suggests that termination may not be flawless; indeed, this finding could help determine why self-terminating processes occasionally look somewhat like exhaustive processes. Interestingly, the only model we have examined able to predict a wider 
degree of slope differences and position effects, the "before versus after" model, assumes that processing rates can speed up after the target is located (Townsend \& Van Zandt, 1990). But then the model is evolving toward selftermination!

In theory, observers might possibly be induced to perform a purely exhaustive scan. Exorbitant penalties for false-" "negative" responses would guarantee exhaustive processing. They would also guarantee very slow response times. It is not our intent to detract from the plasticity of the human information processing system. The importance of "top-down" influences in the search task has been demonstrated many times (Gilford \& Juola, 1976; Jones \& Anderson, 1982; Klatzky \& Atkinson, 1970; Klatzky et al., 1971; Klatzky \& Smith, 1972; Krueger, 1970). With simple stimuli and speed stress, it simply is more parsimonious to consider processes that are terminating to some degree, either concluding abruptly or gradually decelerating after the detection of a target. Furthermore, certain parts of our earlier presentation suggested that such aspects as instructions and display characteristics could influence position and slope effects.

We cannot ignore that RT and error rates are correlated variables. It has been convenient to assume that performance in the search task is error free, or that errors are minimal and constant. There are now powerful selfterminating models that can accurately predict both reaction time and error data and in fact can handle the usual ranges of position effects and slope differences (Broadbent, 1987; Ratcliff, 1978). It might be interesting to build and test comparable exhaustive models that predict slope differences and position effects mainly through variable error rates, although this may seem theoretically pointless. The appeal of Ratcliff's and Broadbent's models is that they can elegantly account for search data and the speed-accuracy tradeoff through the use of psychologically intuitive parameters. Post hoc manipulation of the speed-accuracy tradeoff function does not contribute much to this particular issue.

Finally, questions of a more general nature arise. One of the hallmarks of the information processing approach has been to view cognitive architecture as being composed of distinct subsystems, which interact in converting input to final output. The strictest example of this approach is to view many processing tasks as a series of nonoverlapping and independent subprocesses. If one accepts at least a general version of this scenario as a working postulate, one may still ask about which aspects of the data are (uniquely?) associated with the individual subprocesses. Whether search is parallel, serial, or something else, it is critical whether the various aspects of the data are due to a search/comparison mechanism or to other subprocesses.

Such questions have recently been raised by Stadler and Logan (1989) and by Shulman (1990). Stadler and Logan show that certain structural factors affect RTs in an experiment in which search is unnecessary. These factors could, according to their thesis, be producing some of the major effects associated with memory search experiments in which the same search set is used over a block of trials. In similarity with our argument concerning consistent mapping, these effects need not arise from a process devoted to the comparisons per se. Shulman (1990) emphasizes the probable complexity of the overall information processing system involved in visual search. He points out the difficulty in proving that attentional mechanisms and effects reside in certain processing "boxes" as well as the dangers in simple dichotomies such as "self-terminating" or "exhaustive." It is proposed that other, neglected psychophysical procedures be employed to aid in analysis of attentional processes.

Both these articles raise important issues that have to be confronted by cognitive and perceptual psychologists. They do not, in our opinion, yet constitute strong evidence against the dual postulates that information is transported among functionally distinct (if in some cases overlapping and dependent) subprocesses. Although search or comparisons in memory and visual search tasks may not occur in a single functional subsystem, that is not to say that the termination strategy differs. We hold that, in rapid search performance, processing ends soon after the detection of a target, and that unnecessary processing of all nontargets does not occur in the absence of external inducements by the experimenter.

\section{REFERENCES}

AshBy, F. G. (1976). Pattern matching: Self-terminating or exhaus tive processing? Unpublished master's thesis, Purdue University.

Atkinson, R. C., Holmgren, J. E. \& Juola, J. F. (1969). Processing time as influenced by the number of elements in a visual display. Perception \& Psychophysics, 6, 321-326.

Atkinson, R. C., \&uola, J. F. (1974). Search and decision processes in recognition memory. In D. H. Krantz, R. C. Atkinson, R. D. Luce, \& P. Suppes (Eds.), Contemporary developments in mathematical psychology (Vol. 1, pp. 469-489). San Francisco: W. H. Freeman.

BADDELEY, A. D., \& ECOB, J. R. (1973). Reaction time and short-term memory: Implications of repetition effects for the high-speed exhaustive scan hypothesis. Quarterly Journal of Experimental Psychology, 25, 229-240.

Banks, W. P., \& Prinzmetal, W. (1976). Configurational effects in visual information processing. Perception \& Psychophysics, 19, 361-367.

BeCK, J. (1967). Perceptual grouping produced by line figures. Perception \& Psychophysics, 2, 491-495.

Biederman, I., \& Checkosky, S. F. (1970). Processing redundant information. Journal of Experimental Psychology, 83, 486-490.

Biederman, I., Rabinowitz, J. C., \& Glass, A. L. (1974). On the information extracted from a glance at a scene. Joumal of Experimental Psychology, 103, 597-600.

BJoRk, E. L., \& EsTEs, W. K. (1971). Detection and placement of redundant signal elements in tachistoscopic displays of letters. Perception \& Psychophysics, 9, 439-442.

BraceY, G. W. (1969). Two operations in character recognition: A partial replication. Perception \& Psychophysics, 6, 357-360.

BrIGGs, G. E. (1974). On the predictor variable for choice reaction time. Memory \& Cognition, 2, 575-580.

Briggs, G. E., Blaha, J. (1969). Memory retrieval and central comparison times in information processing. Journal of Experimental Psychology, 79, 395-402.

BRIGGs, G. E., JohNSEN, A. M. (1972). On the nature of central processing in choice reactions. Memory \& Cognition, 1, 91-100.

Briggs, G. E., \& Swanson, J. M. (1970). Encoding, decoding, and central functions in human information processing. Journal of $E x$ perimental Psychology, 86, 296-308. 
Broadeent, D. E., (1987). Structures and strategies: Where are we now? Psychological Research, 49, 73-79.

Burrows, D., \& MurDock, B. B., JR. (1969). Effects of extended practice on high-speed scanning. Journal of Experimental Psychology, 82, 231-237.

Burrows, D., Okada, R. (1971). Serial position effects in high-speed memory search. Perception \& Psychophysics, 10, 305-308.

CARTER, R. C. (1982). Visual search with color. Joumal of Experimental Psychology: Human Perception \& Performance, 8, 127-136.

Cattell, J. M. (1947). The time taken by cerebral operations. In A. T. Poffenberger (Ed.), James McKeen Cattell, man of science: Vol. 1. Psychological research (pp. 107-109). Lancaster, PA: Science Press. (Original work published 1886)

Clifton, C., Birenbaum, S. (1970). Effects of serial position and delay of probe in a memory scan task. Journal of Experimental Psychology, 86, 69-76.

Colegate, R. L., Hoffman, J. E., \& Eriksen, C. W. (1973). Selective encoding from multielement visual displays. Perception \& Psychophysics, 14, 217-224.

CONNER, J. M. (1972). Serial and parallel encoding processes in memory and visual search. Journal of Experimental Psychology, 96, 363-370.

Corballis, M. C. (1967). Serial order in recognition and recall. Journal of Experimental Psychology, 74, 99-105.

Corballis, M. C., Kirby, J., \& Miller, A. (1972). Access to elements of a memorized list. Journal of Experimental Psychology, 94, 185-190.

DonDers, F. C. (1969). On the speed of mental processes. In W. G. Koster (Ed. and Trans.), Attention and performance II (pp. 412-431). Amsterdam: North-Holland. (Original work published 1868-1869)

Duncan, J. (1983). Category effects in visual search: A failure to replicate the "oh-zero" phenomenon. Perception \& Psychophysics, 34, 221-232.

Egeth, H., Folk, C., Mullin, P. (1988). Spatial parallelism in the processing of lines, letters, and lexicality. In B. H. Shep \& S. Ballesteros (Eds.), Object perception: Structure and process (pp. 19-52). Hillsdale, NJ: Erlbaum.

Egeth, H., Jonides, J., W WalL, S. (1972). Parallel processing of multi-element displays. Cognitive Psychology, 3, 674-698.

Egeth, H., Virzi, R. A., \& Garbart, H. (1984). Searching for conjunctively defined targets. Journal of Experimental Psychology: Human Perception \& Performance, 10, 32-39.

Ellis, S. H., \& Chase, W. G. (1971). Parallel processing in item recognition. Perception \& Psychophysics, 10, 379-384.

ERIKSEN, B. A., ERIKSEN, C. W. (1974). Effects of noise letters upon the identification of a target letter in a nonsearch task. Perception \& Psychophysics, 16, 143-149.

Eriksen, C. W., Coluins, J. F. (1969). Temporal course of selective attention. Journal of Experimental Psychology, 80, 254-261.

Eriksen, C. W., Hamlin, R. M., \& DAYE, C. (1973). The effect of flanking letters and digits on speed of identifying a letter. Bulletin of the Psychonomic Society, 2, 400-402.

Eriksen, C. W., \& Hoffman, J. E. (1972). Temporal and spatial characteristics of selective encoding from visual displays. Perception \& Psychophysics, 12, 201-204.

ERIKSEN, C. W., \& RoHrbaUGH, J. W. (1970). Some factors determining efficiency of selective attention. American Journal of Psychology, 83, 330-342.

Eriksen, C. W., Webr, J. M., Fournier, L. R. (1990). How much processing do nonattended stimuli receive? Apparently very little, but.... Perception \& Psychophysics, 47, 477-488.

EsTEs, W. K. (1972). Interactions of signal and background variables in visual processing. Perception \& Psychophysics, 12, 278-286.

Estes, W. K., \& TAYLOR, H. A. (1964). A detection method and probablistic models for assessing information processing from brief visual displays. Proceedings of the National Academy of Sciences, 52, 446-454.

ESTES, W. K., \& WESSEL, D. L. (1966). Reaction time in relation to display size and correctness of response in forced-choice visual signal detection. Perception \& Psychophysics, 1, 369-373.
Fisk, A. D., \& Ackerman, P. L. (1988). Effects of type of responding on memory/visual search: Responding just "yes" or just "no" can lead to inflexible performance. Perception \& Psychophysics, 43, 373-379.

Forrin, B., \& CUnNingham, K. (1973). Recognition time and serial position of probed item in short-term memory. Joumal of Experimental Psychology, 99, 272-279.

GATti, S. V., \& EgEth, H. E. (1978). Failure of spatial selectivity in vision. Bulletin of the Psychonomic Society, 11, 181-184.

Gilford, R. M., \& JUOLA, J. F. (1976). Familiarity effects on memory search and visual search. Bulletin of the Psychonomic Society, $7,142-144$

Green, B. F., \& Anderson, L. K. (1956). Color coding in a visual search task. Joumal of Experimental Psychology, 51, 19-24.

Harris, J. R., Shaw, M. L., \& Al.tom, M. J. (1985). Serial-position curves for reaction time and accuracy in visual search: Tests of a model of overlapping processing. Perception \& Psychophysics, 38, 178-187.

HOCKLEY, W. E. (1984). Analysis of response time distributions in the study of cognitive processes. Journal of Experimental Psychology: Learning, Memory, \& Cognition, 10, 598-615.

Houck, M. R., \& Hoffman, J. E. (1986). Conjunction of color and form without attention: Evidence from an orientation-contingent aftereffect. Journal of Experimental Psychology: Human Perception \& Performance, 12, 186-199.

Johnson, N. F., \& CARnot, M. J. (1990). On time differences in searching for letters in words and nonwords: Do they emerge during the initial encoding or the subsequent scan? Memory \& Cognition, 18, 31-39.

JONES, W. P., \& ANDERSON, J. R. (1982). Semantic categorization and high-speed scanning. Journal of Experimental Psychology: Leaming, Memory, \& Cognition, 8, 237-242.

Jonides, J., \& Gleitman, H. (1972). A conceptual category effect in visual search: $\mathrm{O}$ as letter or as digit. Perception \& Psychophysics, $12,457-460$.

Julesz, B. (1981). Textons, the elements of texture perception, and their interactions. Nature, 290, 91-97.

Klatzky, R. L., \& Atkinson, R. C. (1970). Memory scans based on alternative test stimulus representations. Perception \& Psychophysics, 8, 113-117.

Klatzky, R. L., Juola, J. F., \& Atkinson, R. C. (1971). Test stimulus representation and experimental context effects in memory scanning. Journal of Experimental Psychology, 87, 281-288.

Klatzky, R. L., \& SMith, E. E. (1972). Stimulus expectancy and retrieval from short-term memory. Journal of Experimental Psychology, 94, 101-107.

Klein, R., \& Farrell, M. (1989). Search performance without eye movements. Perception \& Psychophysics, 46, 476-482.

Kristofferson, M. W. (1972a). Effects of practice on character classification performance. Canadian Joumal of Psychology, 26, 54-60.

Kristofferson, M. W. (1972b). When item recognition and visual search functions are similar. Perception \& Psychophysics, 12, 379-384.

KrUeger, L. E. (1970). Effect of stimulus probability on two-choice RT. Joumal of Experimental Psychology, 84, 377-379.

Krueger, L. E. (1984). The category effect in visual search depends on physical rather than conceptual differences. Perception \& Psychophysics, 35, 558-564.

Logan, G. D. (1976). Converging evidence for automatic perceptual processing in visual search. Canadian Journal of Psychology, 30, 193-200.

LuCE, R. D. (1986). Response times. New York: Oxford University Press.

MadDen, D. J., \& Allen, P. A. (1989). Amount and duration of attentional demands during visual search. Perception \& Psychophysics, 45, 577-585.

Mullin, P. A., Egeth, H. E., Mordkoff, J. T. (1988). Redundanttarget detection and processing capacity: The problem of positional preferences. Perception \& Psychophysics, 43, 607-610.

MuRDock, B. B., JR. (1971). A parallel-processing model for scanning. Perception \& Psychophysics, 10, 289-291. 
Navon, D. (1977). Forest before trees: The precedence of global features in visual perception. Cognitive Psychology, 9, 353-383.

Neisser, U. (1964). Visual search. Scientific American, 210, 94-102.

NiCKERSON, R. S. (1966). Response times with a memory-dependent decision task. Journal of Experimental Psychology, 72, 761-769.

Pashler, H. (1987). Detecting conjunctions of color and form: Reassessing the serial search hypothesis. Perception \& Psychophysics, 41, 191-201.

Posner, M. I. (1978). Chronometric explorations of mind. Hillsdale, $\mathrm{NJ}$ : Erlbaum.

Proctor, R. W., \& Healy, A. F. (1987). Task-specific serial position effects in comparisons of multiletter strings. Perception \& Psychophysics, 42, 180-194.

Proctor, R. W., Healy, A. F., \& VAN Zandt, T. (1991). Same-different judgments of multiletter strings: Insensitivity to positional bias and spacing. Perception \& Psychophysics, 49, 62-72.

Ratcuff, R. (1978). A theory of memory retrieval. Psychological Review, 85, 59-108.

RAYNER, K., Fisher, D. L. (1987). Letter processing during eye fixations in visual search. Perception \& Psychophysics, 42, 87-100.

Reeves, A., \& Sperling, G. (1986). Attention gating in short-term visual memory. Psychological Review, 93, 180-206.

SCHNEIDER, W., \& SHIFFrIN, R. M. (1977). Controlled and automatic human information processing: I. Detection, search, and attention. Psychological Review, 84, 1-66.

SCHWEICKERT, R. (1978). A critical path generalization of the additive factor method: Analysis of a Stroop task. Journal of Mathematical Psychology, 18, 105-139.

SCHWEICKERT, R., \& TOWNSEND, J. T. (1989). A trichotomy method: Interactions of factors prolonging sequential and concurrent mental processes in the stochastic PERT networks. Journal of Mathematical Psychology, 33, 328-347.

ShifrRin, R. M. (1988). Attention. In R. C. Atkinson, R. J. Hernstein, G. Lindzey, \& R. D. Luce (Eds.), Stevens' Handbook of experimental psychology (2nd ed., pp. 739-811). New York: Wiley.

Shiffrun, R. M., SCHNEIDER, W. (1977). Controlled and automatic human information processing: II. Perceptual learning, automatic attending, and a general theory. Psychological Review, 84, 127-190.

Shulman, G. L. (1990). Relating attention to visual mechanisms. Perception \& Psychophysics, 47, 199-203.

SimpSON, P. J. (1972). High-speed memory scanning: Stability and generality. Journal of Experimental Psychology, 96, 239-246.

SNODGRASS, J. G., \&ownSEND, J. T. (1980). Comparing parallel and serial models: Theory and implementation. Journal of Experimental Psychology: Human Perception \& Performance, 6, 330-354.

Sperling, G., Budiansky, J., Spivak, J. G., \& Johnson, M. C. (1971). Extremely rapid visual search: The maximum rate of scan ning letters for the presence of a numeral. Science, 174, 307-311.

Stader, M. A., Logan, G. D. (1989). Is there a search in fixedset memory search? Memory \& Cognition, 17, 723-728.

STERNBERG, S. (1966). High-speed scanning in human memory. Science, 153, 652-654.

SternberG, S. (1975). Memory scanning: New findings and current controversies. Quarterly Journal of Experimental Psychology, 27, 1-32.

Strayer, D. L., \& Kramer, A. F. (1990). Attentional requirements of automatic and controlled processing. Journal of Experimental Psychology: Learning, Memory, \& Cognition, 16, 67-82.

Swanson, J. M., \& BRIGGS, G. E. (1969). Information processing as a function of speed versus accuracy. Journal of Experimental Psychology, 81, 223-229.

Theios, J. (1975). The components of response latency in simple human information processing tasks. In P. M. A. Rabbitt \& S. Dornic (Eds.), Attention and performance $V$ (pp. 418-440). London: Academic Press.

Theios, J., \& Muise, J. G. (1977). The word identification process in reading. In N. J. Castellan, Jr., D. P. Pisoni, \& G. R. Potts (Eds.), Cognitive theory (Vol. 2, pp. 289-321). Hillsdale, NJ: Erlbaum.

Theios, J., Smith, P. G., Haviland, S. E., Traupmann, J., \& MoY, M. C. (1973). Memory scanning as a serial self-terminating process. Journal of Experimental Psychology, 97, 323-336.

TowNSEND, J. T. (1972). Some results concerning the identifiability of parallel and serial processes. British Joumal of Mathematical \& Statistical Psychology, 25, 168-199.

TOWNSEND, J. T. (1974). Issues and models concerning the processing of a finite number of inputs. In B. H. Kantowitz (Ed.), Human information processing: Tutorials in performance and cognition (pp. 133-168). Hillsdale, NJ: Erlbaum.

TowNSEND, J. T. (1990). Serial versus parallel processing: Sometimes they look like Tweedledum and Tweedledee but they can (and should) be distinguished. Psychological Science, 1, 46-54.

TownSEND, J. T., AshBY, F. G. (1983). The stochastic modeling of elementary psychological processes. Cambridge: Cambridge University Press.

Townsend, J. T., \& Evans, R. J. (1983). A systems approach to parallel-serial testability and visual feature processing. In H. G. Geissler (Ed.), Modern issues in perception (pp. 166-191). Amsterdam: North-Holland.

TOWNSEND, J. T., \& Roos, R. N. (1973). Search reaction time for single targets in multiletter stimuli with brief visual displays. Memory \& Cognition, 1, 319-332.

TownSEND, J. T., \& SCHWEICKERT, R. (1989). Toward the trichotomy method of reaction times: Laying the foundation of stochastic mental networks. Mathematical Psychology, 33, 309-327.

TownSEND, J. T., \& VAN ZANDT, T. (1990). New theoretical results on testing self-terminating vs. exhaustive processing in rapid search experiments. In H. G. Geissler (Ed.), Psychological explorations of mental structures (pp. 469-489). Toronto: Hogrefe \& Huber.

Treisman, A., \& Gormican, S. (1988). Feature analysis in early vision: Evidence from search asymmetries. Psychological Review, 95 , $15-48$.

Treisman, A., Sykes, M., \& Gelade, G. (1977). Selective attention and stimulus integration. In S. Dornic (Ed.), Attention and performance VI (pp. 333-361). Hillsdale, NJ: Erlbaum.

Treisman, M., \& Doctor, E. (1987). Memory scanning: A comparison of the dynamic stack and exhaustive serial scan models, with an extension of the latter. Acta Psychologica, 64, 39-92

VAN der Heijden, A. H. C. (1975). Some evidence for a limited capacity parallel self-terminating process in simple visual search tasks. Acta Psychologica, 39, 21-41.

Van der Heijden, A. H. C., La HeiJ, W., Boer, J. P. A. (1983) Parallel processing of redundant targets in simple visual search tasks. Psychological Research, 45, 235-254.

Van der Heijden, A. H. C., Menckenberg, H. W. (1974). Some evidence for a self-terminating process in simple visual search tasks. Acta Psychologica, 38, 169-181.

WELFord, A. T. (ED.) (1980). Reaction times. London: Academic Press.

Wijers, A. A., Mulder, G., Okita, T., Mulder, L. J. (1989). Event-related potentials during memory search and selective attention to letter size and color. Psychophysiology, 26, 529-547.

WOLFORD, G. L., WeSSEL, D. L., \& EsTES, W. K. (1968). Further evidence concerning scanning and sampling assumptions of visual detection models. Perception \& Psychophysics, 3, 439-444.

WUNDT, W. (1894). Lectures on human and animal psychology. London: Swan Sonneschein.

YANTIS, S., JonidES, J. (1984). Abrupt visual onsets and selective attention: Evidence from visual search. Journal of Experimental Psychology: Human Perception \& Performance, 10, 601-620.

\section{APPENDIX}

Theoretical details and proofs of new and recent results (e.g., generalizations of previous theorems) are presented explicitly here for the following reasons: (1) self-containment of treatment; (2) availability for examination of new results as well as those in publications not accessible to some readers; (3) explicit formulas may be employed by others for further modeling; (4) suggestions by reviewers.

\section{Serial Processes}

Suppose that a rapid search experiment is performed, in which all items, targets and nontargets, are placed in each position in 
the search set with equal probability. On any given trial, there is an equal probability that a positive or negative search set will be presented, and on positive trials only one target is presented. For a search set of size $n$, there are $n$ ! possible orders in which search set positions could be processed. Let $P_{n}(j)$ be the probability that order $j$ is selected for $n$ items, where $j=1,2, \ldots$, $n !$. Allow the random variable between the target and the search set to vary with position in the search set and with the processing path, as well as with load and the identity (positive or negative) of the item. This comparison time is represented by the random variable $T_{i j}^{+}(n)$ for a target in position $i$ on processing path $j$. Similarly, $T_{i j}^{-}(n)$ is the random variable for the nontarget processing time.

Two important assumptions are that (1) the probability of taking any particular processing path does not depend on the presence or absence of a target; and (2) given a particular processing path and position, the negative processing time distribution is invariant over the presence or absence of a target and its placement. We have not investigated the consequences of violating Assumption 1. Assumption 2 may be weakened in such a way that the models begin to approximate (actually, evolve into) selfterminating models, but then they are no longer exhaustive processes. For the serial exhaustive model, total processing time (for ease of discourse we will call this RT) for a negative trial is

$$
\begin{aligned}
E\left[\mathrm{RT}^{-}(n)\right] & =\sum_{j=1}^{n !} \mathrm{P}_{n}(j) E\left[\mathrm{RT}^{-}(n) \mid \text { processing path } j\right] \\
& =\sum_{j=1}^{n !} \mathrm{P}_{n}(j) \sum_{i=1}^{n} E\left[T_{i j}^{-}(n)\right] \\
& =\sum_{i=1}^{n} \sum_{j=1}^{n !} \mathrm{P}_{n}(j) E\left[T_{i j}^{-}(n)\right] \\
& =\sum_{i=1}^{n} E\left[T_{i}^{-}(n)\right]=n E\left[T^{-} .(n)\right]
\end{aligned}
$$

Mean RT for a positive trial is

$$
\begin{aligned}
E & {\left[\mathrm{RT}^{+}(n)\right] } \\
& =\sum_{j=1}^{n !} \mathrm{P}_{n}(j) E\left[\mathrm{RT}^{+}(n) \mid \text { processing path } j\right] \\
& =\sum_{j=1}^{n !} \mathrm{P}_{n}(j)(1 / n) \sum_{i=1}^{n} E\left[\mathrm{RT}^{+}(n) \mid \begin{array}{c}
\text { processing path } j, \\
\text { target in position } i]
\end{array}\right. \\
& =\sum_{j=1}^{n !} \mathrm{P}_{n}(j)(1 / n) \sum_{i=1}^{n}\left(E\left[T_{i j}^{+}(n)\right]+\sum_{k \neq i}^{n} E\left[T_{k j}^{-}(n)\right]\right) \\
& =E\left[T^{+} \ldots(n)\right]+(n-1) E\left[T^{-} \ldots(n)\right],
\end{aligned}
$$

where, according to convention, the subscripted dots indicate that the associated indices have been "averaged over." Thus, the expectations $E\left[T^{+} .(n)\right]$ and $E\left[T_{. .}^{-}(n)\right]$ are the average processing times for a target and nontarget, respectively, over position and processing path in a search set of size $n$. For brevity, we will now write these expectations as $E\left[T^{+}(n)\right]$ and $E\left[T^{-}(n)\right]$. We are now in a position to state the following propositions, applicable to the domain outlined above.

Proposition 1. For the general exhaustive serial model outlined above, in which individual processing times can vary with position, processing path, load, and identity, then the ratio of negative to positive slopes of the set-size functions cannot exceed $n /(n-1)$ for any positive integer value of $n$. That is,

$$
\frac{E\left[\mathrm{RT}^{-}(n)\right]-E\left[\mathrm{RT}^{-}(n-1)\right]}{E\left[\mathrm{RT}^{+}(n)\right]-E\left[\mathrm{RT}^{+}(n-1)\right]}<\frac{n}{n-1} .
$$

Proof. Refer to Townsend and Van Zandt (1990, pp. 478-479). In this proof, the assumption (stated above) that the positioning of the target by the experimenter is random is needed. All search studies cited here obey this provision, unless stated otherwise.
Proposition 2. Under the same constraints as Proposition 1, this class of exhaustive serial models must be of supercapacity to encompass strong position effects.

Proof. Strong position effects are of the same nature and magnitude as those produced by serial self-terminating models with fixed search path. To say that a serial exhaustive model can produce strong position effects is equivalent to stipulating that, for all $n \geq j$,

$$
\begin{aligned}
E\left[\mathrm{RT}^{+}(n) \mid \text { target in position } j\right] & =\sum_{i \neq j}^{n} E\left[T_{i .}^{-}\right]+E\left[T_{j .}^{+}\right] \\
& =E\left[\mathrm{RT}^{-}(j)\right] \\
& =j E\left[T^{-}(j)\right] .
\end{aligned}
$$

The last two expressions are not indexed by the set size $n$ precisely because, in the standard serial self-terminating model, the $j$ th position will always be reached in $j$ steps. Furthermore, each step will take the same amount of time and be independent from $n$ and the presence of a target.

Now, set $E\left[\mathrm{RT}^{+}(n) \mid\right.$ target in position $\left.j\right]$ equal to $j E\left[T^{-}(j)\right]$ and average over target placements:

$$
\begin{aligned}
E\left[\mathrm{RT}^{+}(n)\right] & =(1 / n) \sum_{j=1}^{n} E\left[\mathrm{RT}^{+}(n) \mid \text { target in position } j\right] \\
& =E\left[T^{+}(n)\right]+(n-1) E\left[T^{-}(n)\right] \\
& =(1 / n) \sum_{j=1}^{n} j E\left[T^{-}(j)\right] .
\end{aligned}
$$

Also,

$$
\begin{aligned}
E\left[\mathrm{RT}^{+}(n+1)\right] \\
\quad=(1 /(n+1)) \sum_{j=1}^{n+1} E\left[\mathrm{RT}^{+}(n+1) \mid \text { target in position } j\right] \\
\quad=(1 /(n+1)) \sum_{j=1}^{n+1} j E\left[T^{-}(j)\right] \\
\quad=(n /(n+1)) E\left[\mathrm{RT}^{+}(n)\right]+E\left[T^{-}(n+1)\right] .
\end{aligned}
$$

This implies that

$$
\begin{aligned}
& (n+1)(n-1) E\left[T^{-}(n+1)\right]+(n+1) E\left[T^{+}(n+1)\right] \\
& \quad=n(n-1) E\left[T^{-}(n)\right]+n E\left[T^{+}(n)\right] .
\end{aligned}
$$

Substitute $\alpha E\left[T^{-}(n)\right]$ for $E\left[T^{-}(n+1)\right]$ and $\beta E\left[T^{+}(n)\right]$ for $E\left[T^{+}(n+1)\right]$ in the equation above. If $\alpha$ or $\beta$ is less than one, the corresponding process must be supercapacity. Collecting terms, we see that

$$
(n-1)[\alpha(n+1)-n] E\left[T^{-}(n)\right]+[\beta(n+1)-n] E\left[T^{+}(n)\right]=0 .
$$

For the sum to equal zero, one of the coefficients involving $\alpha$ or $\beta$ must be negative. This means that either $\alpha<n /(n+1)$, or $\beta<n /(n+1)$. Therefore, one of the processes must be supercapacity.

\section{Parallel Processes}

The examination of parallel models will proceed by expressing the mean processing times in terms of the distribution functions of $T^{-}(n)$ and $T^{+}(n)$. All proofs will be constructed by observing the change in processing time from set size $n=1$ to $n=$ 2 . The finishing time distribution for the random variable $T^{+}(n)$ will be written as $G^{+}(t, n)$, and likewise the distribution for $T^{-}(n)$ will be written $G^{-}(t, n)$. Because the items are processed independently and in parallel, order and position considerations have been abandoned. Although the distributions may still be assumed to depend on position, this assumption is not necessary for the results we present here. 
Before proceeding, note that the mean RTs can now be expressed as

$$
E\left[\operatorname{RT}^{-}(n)\right]=\int_{0}^{\infty}\left[1-G^{-}(t, n)^{n}\right] d t
$$

and

$$
E\left[\mathrm{RT}^{+}(n)\right]=\int_{0}^{\infty}\left[1-G^{+}(t, n) G^{-}(t, n)^{n-1}\right] d t
$$

when search is exhaustive. The changes in RT from $n=1$ to $n=2$ are then

$$
\Delta E\left(\mathrm{RT}^{-}\right)=\int_{0}^{\infty}\left[G^{-}(t, 1)-G^{-}(t, 2)^{2}\right] d t
$$

and

$$
\Delta E\left(\mathrm{RT}^{+}\right)=\int_{0}^{\infty}\left[G^{+}(t, 1)-G^{+}(t, 2) G^{-}(t, 2)\right] d t .
$$

PROPOSITION 3. If both the target and the nontarget processes are of unlimited capacity, a slope ratio greater than one can occur only if positive responses are slower than negative responses.

Proof. We proceed as in Townsend and Van Zandt (1990) but with greater generality. If both processes are of unlimited capacity, the distribution functions are independent of $n$. That is, $G^{-}(t, 1)=G^{-}(t, 2)=G^{-}(t)$ and $G^{+}(t, 1)=G^{+}(t, 2)=G^{+}(t)$. So, the changes in RT become

and

$$
\Delta E\left(\mathrm{RT}^{-}\right)=\int_{0}^{\infty} G^{-}(t)\left[1-G^{-}(t)\right] d t
$$

$$
\Delta E\left(\mathrm{RT}^{+}\right)=\int_{0}^{\infty} G^{+}(t)\left[1-G^{-}(t)\right] d t .
$$

Set $\Delta E\left[\mathrm{RT}^{-}\right]=\alpha \Delta E\left[\mathrm{RT}^{+}\right]$, or

$$
\int_{0}^{\infty} G^{-}(t)\left[1-G^{-}(t)\right] d t=\alpha \int_{0}^{\infty} G^{+}(t)\left[1-G^{-}(t)\right] d t .
$$

Because $G^{-}(t), G^{+}(t)$, and $\left[1-G^{-}(t)\right]$ are all positive, $G^{+}(t)$ must be less than $G^{-}(t)$ for $\alpha>1$. This means that unless $\alpha=1$, $E\left[\mathrm{RT}^{-}(n)\right]<E\left[\mathrm{RT}^{+}(n)\right]$.

Proposition 4. If the nontarget process is of unlimited capacity and all processing times are equal when $n=1$, the target process must be of supercapacity to produce a slope ratio greater than 1 .

Proof. Again the procedure is based on Townsend and Van Zandt but with a more general result. Because the nontarget process is of unlimited capacity, $G^{-}(t, 1)=G^{-}(t, 2)=G(t)$. For all processing times to be equal at $n=1, G^{+}(t, 1)=G^{-}(t, 1)=$ $G(t)$. The changes in RT are now

$$
\Delta E\left(\mathrm{RT}^{-}\right)=\int_{0}^{\infty}\left[G(t)-G(t)^{2}\right] d t
$$

and

$$
\Delta E\left(\mathrm{RT}^{+}\right)=\int_{0}^{\infty}\left[G(t)-G(t) G^{+}(t, 2)\right] d t .
$$

Set $\Delta E\left[\mathrm{RT}^{-}\right]=\alpha \Delta E\left[\mathrm{RT}^{+}\right]$, or

$$
\int_{0}^{\infty}\left[G(t)-G(t)^{2}\right] d t=\alpha \int_{0}^{\infty}\left[G(t)-G(t) G^{+}(t, 2)\right] d t
$$

Both $G(t)-G(t)^{2}$ and $G(t)-G(t) G^{+}(t, 2)$ are positive. Therefore, if $\alpha>1$, then $G^{+}(t, 2)>G(t)=G^{+}(t, 1)$. This means that the mean target processing time is speeding up as the load increases; the target process must be of supercapacity.

Proposition 5. An independent exponential, parallel exhaustive model that presumes linear negative set-size functions cannot produce strong position effects.
Proof. Refer to Townsend and Van Zandt (1990), pages 485-486.

Although Townsend and Van Zandt's (1990) results concerning limited capacity processes were not as strong as we would have liked, we now state new and stronger results about exhaustive parallel processes in which the finishing times for each item are exponentially distributed. We will again allow the target distribution to depend on the target's position. Let $T_{i}^{+}$be the random variable representing the total completion time on a positive trial in which the target item was located in position $i$ in the search set; that is, the sum of processing times for $n-1$ nontargets and the target in position $i$. Let $n$ represent the size of the search set, and let $v_{i}^{+}(n)$ be the processing rate for the target in position $i$. Also let $v^{-}(n)$ be the processing rate for every nontarget. Note that the nontarget distributions are independent of position.

Suppose that a rapid search experiment is performed in which it is observed that the negative set-size function has slope $r$, the positive set-size function has slope $s$, and for a given load $n$, it is observed that the position effect function has slope $p(n)$. The quantity $s n$ is the mean of $E\left[T_{j}^{+}\right]$over all $j$-an observed point on the positive set-size function. We will assume for simplicity's sake that both the set-size functions and the position effect functions are linear. To fit the observed pattern of slopes and position effects, the mean processing times $E\left[T_{j}^{+}\right], j=1$, $2, \ldots, n$ must satisfy the following system of equations for all $n$ :

$$
\begin{gathered}
E\left[T_{2}^{+}\right]-E\left[T_{1}^{+}\right]=p(n) \\
E\left[T_{3}^{+}\right]-E\left[T_{2}^{+}\right]=p(n) \\
\ldots \\
E\left[T_{n}^{+}\right]-E\left[T_{n-1}^{+}\right]=p(n) \\
(1 / n)\left[E\left(T_{1}^{+}\right)+E\left(T_{2}^{+}\right)+\ldots+E\left(T_{n}^{+}\right)\right]=s n,
\end{gathered}
$$

assuming that the target is placed in any one of the $n$ possible locations with equal probability. The first $n-1$ equations in this system merely reflect the conditions on the mean processing times necessary for the position effect function to be linear with slope $p(n)$, where $p(n)$ may be positive or negative. That is, moving the target from position $i$ to position $i+1$ must add the quantity $p(n)$ to the processing time. The last equation reflects the condition that the mean processing time across all target placements must equal the appropriate point on the positive setsize function. This system has the solution

$$
E\left[T_{i}^{+}\right]=\left(\frac{2 i-n-1}{2}\right) p(n)+s n .
$$

Recall that the slope of the negative set-size function is $r$. The negative rate $v^{-}(n)$ can be found through the equation

$$
v^{-}(n)=\frac{\sum_{i=1}^{n}(1 / i)}{n r}
$$

This relation between the negative slope and the negative rate assumes a linear negative set-size function, and parallel, independent exponential, exhaustive processing (Townsend \& Roos, 1973).

Proposition 6. For an independent exponential, exhaustive process which produces linear set-size and position functions, the slopes of these functions must satisfy the following conditions for all $n$ :

$$
s n-\left(\frac{n-1}{2}\right)|p(n)|>\frac{\sum_{i=1}^{n-1}(1 / i)}{v^{-}(n)}
$$


and

$$
s n>\frac{\sum_{i=1}^{n-1}(1 / i)}{v^{-}(n)} \text {. }
$$

The slopes $r, s$, and $p(n)$ are as defined above. If Condition 1 is not satisfied, no positive rates $v_{i}^{+}(n)$ exist to produce the position effects. If Condition 2 is not satisfied, no positive rates $v_{i}^{+}(n)$ exist to produce the set-size effects.

Proof. The expression for $E\left(T_{i}^{\dagger}\right)$ imposes these bounds; as $v_{i}^{+}(n)$ goes to infinity, or as the target process becomes infinitely fast, the processing time for a positive trial with $n$ items tends to the processing time for a negative trial with $n-1$ items. That is,

$$
\lim _{v_{i}^{+}(n)^{-\infty}} E\left(T_{i}^{+}\right)=\frac{\sum_{i=1}^{n-1}(1 / i)}{v^{-}(n)} .
$$

This can be shown formally, by writing out the expression for $E\left(T_{i}^{+}\right)$in terms of exponential mean finishing times, but for now it should be intuitive that this relation must hold: $E\left(T_{i}^{+}\right)$must be at least as long as the time to process the $n-1$ nontargets in the display. Therefore

$$
\left(\frac{2 i-n-1}{2}\right) p(n)+s n>\frac{\sum_{i=1}^{n-1}(1 / i)}{v^{-}(n)} .
$$

The absolute value of $(2 i-n-1) / 2$ is largest when $i=1$ and $i=n$. If $p(n)$ is positive, $E\left(T_{i}^{*}\right)$ is smallest when $i=1$ :

$$
E\left(T_{i}^{+}\right)=s n-\left(\frac{n-1}{2}\right) p(n) .
$$

If $p(n)$ is negative, $E\left(T_{i}^{+}\right)$is smallest when $i=n$ :

$$
E\left(T_{n}^{+}\right)=s n+\left(\frac{n-1}{2}\right) p(n) .
$$

Because the inequality must hold for all $i$, regardless of $p(n)$, it can be seen that

$$
s n-\left(\frac{n-1}{2}\right)|p(n)|>\frac{\sum_{i=1}^{n-1}(1 / i)}{v^{-}(n)},
$$

from which it follows that

$$
s n>\frac{\sum_{i=1}^{n-1}(1 / i)}{v^{-}(n)} .
$$

The first inequality reflects the condition that must hold to ensure the existence of rates $v_{i}^{+}(n)$ that can produce the observed position effects. The second inequality reflects the condition that must hold to ensure the existence of any rate $v_{i}^{+}(n)$ that can produce the observed mean processing time. If either of these inequalities is violated for a particular $n$ or $i$, the mean positive RT must be faster than the time to process the $n-1$ nontargets, and so no positive rate greater than zero exists that can produce the pattern of mean RTs.

We can use Conditions 1 and 2 to explore the range of slope differences and position effects that this exhaustive model can produce. First, express $s n$ (the mean positive processing time for a given load $n$ ) as $\alpha r n$, where $\alpha$ is some positive constant and $r$ is the slope of the negative set-size function. That is, let the positive processing time be proportional to the negative processing time. If $\alpha<1$, the positive set-size function increases less rapidly than the negative set-size function. If $\alpha=1$, the set-size functions are parallel.

Proposition 7. An independent exponential, parallel exhaustive model with linear set-size functions and position effects can produce no slope ratio greater than 3:2.

Proof. From the expression for $v^{-}(n)$ given above, Condition 2 can be rewritten as

$$
\alpha r n>\frac{\sum_{i=1}^{n-1}(1 / i)}{\sum_{i=1}^{n}(1 / i) / n r},
$$

or

$$
\alpha>\frac{\sum_{i=1}^{n-1}(1 / i)}{\sum_{i=1}^{n}(1 / i)} .
$$

Thus, the smallest value that $\alpha$ can assume is $2 / 3$, and then only when the load is two. This means a maximum positive to negative slope ratio of 3:2. As $n$ grows larger, $\alpha$ is further constrained and eventually cannot be less than one.

PROPOSITION 8. In the preceding independent exponential, parallel exhaustive model, the slope of the position effect function is constrained to be between $-4 / 3$ and 4/3. As the set size increases, the range of possible slopes decreases, and the position effects must become flat for large n; similarly, the set-size functions must become parallel.

Proof. Without loss of generality, assume that the negative slope $r$ equals one. This assumption only involves a transformation of the time scale. Substituting $\alpha r n=\alpha n$ for $s n$, Condition 1 can be rewritten as

$$
\alpha n-\left(\frac{n-1}{2}\right)|p(n)|>\frac{\sum_{i=1}^{n-1}(1 / i)}{\left[\sum_{i=1}^{n}(1 / i) / n\right]},
$$

which can be simplified to yield

$$
\frac{2 n}{n-1}\left[\alpha-\frac{\sum_{i=1}^{n-1}(1 / i)}{\sum_{i=1}^{n}(1 / i)}\right]>|p(n)| .
$$

If $\alpha=1$, the set-size functions are parallel. If $\alpha<1$, the positive slope is less than the negative slope. The absolute value of $p(n)$ can be largest when $n=2$ and $\alpha=1$. In this case, the slope of the position effect function must be between $-4 / 3$ and $4 / 3$. As $n$ grows larger, however, the range of $p(n)$ decreases, until $p(n)$ finally becomes bounded by $2(\alpha-1)$; if $\alpha=1$, the position effect functions must become flat.

Notice that if $\alpha<1$ for large $n$, the inequality is violated because $|p(n)|$ must be nonnegative. Hence, for large $n$, the occurrence of slope differences prohibits the existence of exhaustive processing rates that can accommodate either position effects or the slope differences between the set-size functions.

(Manuscript received July 15, 1992; revision accepted for publication August $27,1992$. ) 